\title{
Evaluation of the Hypoglycemic Potential of Leaves Extract of Spondias pinnata (L.f.) Kurz. from Nepal
}

\author{
Kusum Sai $\mathbb{D}^{1},{ }^{1}$ Sumit Bahadur Baruwal Chhetri $\left(\mathbb{D}^{1},{ }^{1}\right.$ Shankar Raj Devkota $\left(\mathbb{D}^{2}\right.$, \\ and Deepa Khatri $\mathbb{1}^{1}$ \\ ${ }^{1}$ Department of Pharmaceutical Sciences, School of Health and Allied Sciences, Pokhara University, Pokhara 33700, Nepal \\ ${ }^{2}$ Department of Biochemistry and Molecular Biology, Monash University, Clayton, VIC 3800, Australia \\ Correspondence should be addressed to Kusum Sai; kusumsai100@gmail.com
}

Received 2 May 2021; Revised 13 June 2021; Accepted 21 June 2021; Published 28 June 2021

Academic Editor: Juei Tang Cheng

Copyright (c) 2021 Kusum Sai et al. This is an open access article distributed under the Creative Commons Attribution License, which permits unrestricted use, distribution, and reproduction in any medium, provided the original work is properly cited.

\begin{abstract}
Spondias pinnata (L.f.) Kurz. (family: Anacardiaceae) is a wild deciduous tree indigenous to southeast Asian countries. Different parts of this plant are used traditionally for the treatment and cure of various disorders and illnesses. S. pinnata leaves are used to prevent and treat diabetes in traditional Balinese medicine. However, scientific study on the antihyperglycemic effect of its leaves has not been reported yet. Therefore, this study aims to perform phytochemical screening and investigate the hypoglycemic potential of $S$. pinnata leaves extract. Preliminary phytochemical screening of the hydroethanolic extract was performed following the standard tests. In vivo hypoglycemic activity of the leaves extract was evaluated using normal and glucose-loaded rats. The results displayed the presence of phytochemical constituents such as saponins, phenolic compounds, flavonoids, and terpenoids. S. pinnata $(500 \mathrm{mg} / \mathrm{kg})$ and metformin $(100 \mathrm{mg} / \mathrm{kg})$ exhibited a significant $(p<0.05)$ decrease in blood glucose level at 1,2 , and $3 \mathrm{~h}$ in normal rats when compared to the control group. Metformin- $(100 \mathrm{mg} / \mathrm{kg})$ - and $S$. pinnata- $(500 \mathrm{mg} / \mathrm{kg})$ - treated groups showed a maximum decrease in the blood glucose level at $3 \mathrm{~h}$ after single-dose administration in the oral glucose tolerance test (OGTT). In conclusion, $S$. pinnata leaves possess a significant hypoglycemic activity in the animal model and thus support its traditional use to treat diabetes. Therefore, a detailed mechanism-based study and isolation of bioactive compounds from S. pinnata leaves would be beneficial in the future for the search of new hypoglycemic agents.
\end{abstract}

\section{Introduction}

Diabetes mellitus is a metabolic disorder characterized by hyperglycemia caused due to defects in insulin production, insulin sensitivity, or both. The major complications of diabetes include abnormally high blood sugar levels and blood vessel diseases, which may further cause long-term damage to vital organs such as the eye, kidney, nerves, and heart [1]. In recent years, the prevalence of diabetes has increased worldwide. The global prevalence of diabetes is estimated to be $9.3 \%$ in 2019 , rising to $10.2 \%$ by 2030 and $10.9 \%$ by 2045 [2]. The International Diabetes Federation (IDF) has reported that approximately 463 million people (20-79 years) are living with diabetes in 2019, and the number is projected to rise to 578 million by 2030 and 700 million by 2045 . Diabetes has caused around 4.2 million deaths worldwide [3]. Treatment and management of diabetes include a healthy diet, physical exercise, medications to lower blood sugar levels, and insulin therapy [4]. Inhibition of enzymes involved in the decomposition of carbohydrates such as $\alpha$-amylase and $\alpha$-glucosidase is an important therapeutic approach for reducing postprandial hyperglycemia [5]. Treatment of diabetes with insulin and other synthetic drugs is associated with various side effects. Therefore, searching for more effective and safer hypoglycemic drugs is still going on all over the world.

Spondias pinnata (L.f.) Kurz. (Anacardiaceae) (Figure 1), commonly known as hog plum or wild mango, is a deciduous tree native to Malesia and distributed throughout India, Nepal, Bhutan, Southern China, and Myanmar [6,7]. The plant bears edible fruits which are 


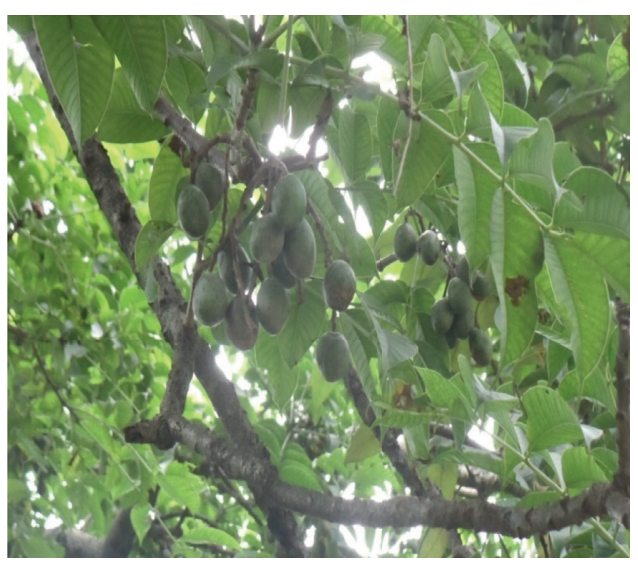

(a)

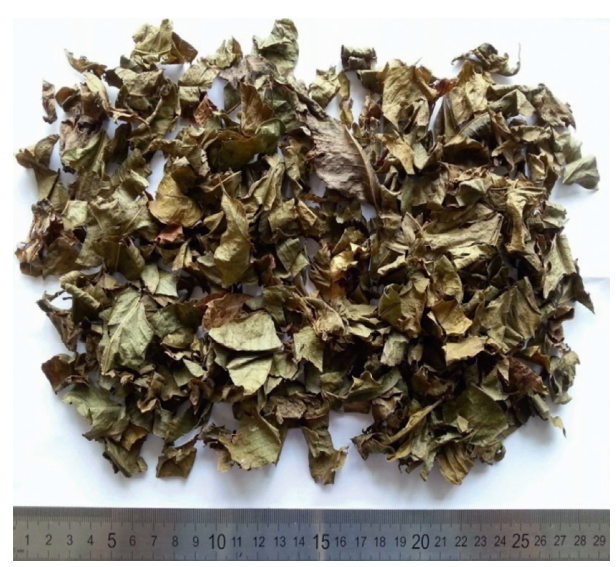

(b)

Figure 1: (a) Leaves and fruits of S. pinnata. (b) Dried leaves of S. pinnata.

eaten fresh or pickled [8]. Different parts of S. pinnata are used for medicinal purposes by indigenous people. In Balinese ethnobotanical tradition, the leaves are used to prepare an herbal drink called "Loloh" to treat urolithiasis, heartburn, and diabetes and to boost overall body health [9]. The bark is used for treating dysentery, muscular rheumatism, and diabetes mellitus in Ayurvedic medicine [10]. Similarly, bark juice is given for diarrhea, dysentery, stomachache, and rheumatism in hilly regions of Nepal [8]. Flowers are used in curry and for flavoring in Illam, Nepal [11]. Plant latex is applied for treating wounds and cuts in far-west Nepal [12]. S. pinnata possesses various chemical constituents. Its unripe fruit contains methyl caffeate and rhamnetin-3-O-sophoroside [13]; the bark contains methyl gallate [14]; the aerial part contains stigmast-4-en-3-one, $\beta$-sitosterol, and $\beta$-sitosterol $\beta$-D-glucoside [15]. Hypoglycemic activity of S. pinnata bark has been reported previously [16]. Likewise, antidiabetic and antilipidemic properties of the fruit extract have also been reported [17]. The leaves extract of $S$. pinnata possess antimicrobial and antiviral properties and contain a large number of phenolic compounds exhibiting free radical scavenging ability [18].

However, the hypoglycemic activity of S. pinnata leaves has not been documented yet. Therefore, for the first time, the hypoglycemic potential of leaves extract was investigated in normal and glucose-loaded rats as a preliminary effort to reveal its antihyperglycemic properties.

\section{Materials and Methods}

2.1. Chemicals and Reagents. Ferric chloride hexahydrate $\left(\mathrm{FeCl}_{3} \cdot 6 \mathrm{H}_{2} \mathrm{O}\right)$, potassium iodide, iodine, mercuric chloride, and picric acid were purchased from Sigma-Aldrich, USA. Ethanol, hydrochloric acid, sulphuric acid, chloroform, benzene, ammonia, and sodium hydroxide were procured from Merck, Germany, and sodium chloride and gelatin were purchased from Qualigens Fine Chemicals, India. The drugs metformin and glucose were obtained from Times Pharmaceuticals, Nepal. All chemicals used were of analytical grade.
2.2. Plant Material and Extraction. Fresh leaves of S. pinnata were collected from Kaski district, Gandaki province, Nepal, and identified with the help of locals and using literature [8]. The voucher specimen (PUCD-201807) was authenticated by botanist Dr Radheshyam Kayastha and was deposited in the Pharmacognosy laboratory, Pokhara University, for future reference. Dried leaves $(30 \mathrm{~g})$ were extracted twice with $80 \%$ ethanol in the ratio of $1: 8$ for $24 \mathrm{~h}$ at room temperature in a closed vessel with occasional shaking. The filtered extracts were then dried in a rotary evaporator (Heidolph, Germany) to obtain a viscous mass and stored at $4^{\circ} \mathrm{C}$ until use. The percentage extract yield value was calculated using the following equation:

$$
\operatorname{yield}(\%)=\left(\frac{\text { weight of extract }}{\text { weight of dried leaves }}\right) \times 100 \text {. }
$$

2.3. Phytochemical Screening. The hydroethanolic extract of S. pinnata leaves was tested for potential chemical constituents through preliminary phytochemical screening using standard methods $[19,20]$.

2.4. Experimental Animals. Male albino Wistar rats of 50-60 g were purchased from Pokhara, Nepal, and were housed in polypropylene cages under standard laboratory conditions. The temperature of the facility was maintained at $25 \pm 3^{\circ} \mathrm{C}$, humidity $55 \pm 5 \%$, and light/darkness alternated $12 \mathrm{~h}$ apart. Rats were allowed to grow and acclimatize in the laboratory condition for 6 weeks and fed with standard diet and water ad libitum. After acclimatization, experiments were performed in rats weighing $150-180 \mathrm{~g}$. They were fasted overnight before the experiment, allowing free access to water.

2.5. Ethical Clearance. Ethical clearance to conduct the in vivo study was obtained from the Institutional Review Committee (IRC) of the Pokhara University Research 
Center (ref. no.:148-074-075). All activities using animals were conducted following the ethical guidelines.

2.6. Acute Toxicity Study. The acute toxicity of S. pinnata leaves extract was determined using male albino Wistar rats (150-180 g) maintained under standard conditions. Overnight fasted rats were taken and divided into four groups of five animals each $(n=5)$. Different doses $(250,500,1000$, and $2000 \mathrm{mg} / \mathrm{kg}$ body weight) of the extract were administered orally. Then, the animals were observed for general signs of toxicity for 14 days [21].

\subsection{Experimental Protocol for In Vivo Hypoglycemic Activity}

2.7.1. Hypoglycemic Effect in Normal Rats. Rats were kept fasting overnight with free access to water and were divided into four groups, each containing five animals $(n=5)$. Group I was treated with normal saline $(0.9 \% \mathrm{NaCl})$ and served as a normal control group. Groups II and III were treated with S. pinnata leaves extract at the doses of $250 \mathrm{mg} / \mathrm{kg}$ and $500 \mathrm{mg} / \mathrm{kg}$ body weight, respectively, and Group IV was treated with standard drug metformin $(100 \mathrm{mg} / \mathrm{kg}$ body weight). Fasting blood glucose levels were determined at the beginning of the experiment. After the oral administration of the test samples, blood glucose levels were measured at $0.5,1,2$, and $3 \mathrm{~h}$ with the help of a clinical glucometer.

2.7.2. Hypoglycemic Effect in Glucose-Induced Hyperglycemic Rats (OGTT). Oral glucose tolerance test (OGTT) was performed in overnight-fasted normal rats [22] with some modifications. Rats were randomly selected and divided into four groups $(n=5)$. Group I served as a normal control group treated with normal saline $(0.9 \% \mathrm{NaCl})$. Groups II and III were treated with $S$. pinnata leaves extract at $250 \mathrm{mg} / \mathrm{kg}$ and $500 \mathrm{mg} / \mathrm{kg}$ body weight, respectively, and Group IV was treated with the standard drug metformin $(100 \mathrm{mg} / \mathrm{kg}$ body weight). After $30 \mathrm{~min}$, glucose was administered orally to rats of all the groups $(2 \mathrm{~g} / \mathrm{kg}$ body weight). Blood samples were collected at $0,0.5,1,2$, and $3 \mathrm{~h}$ of glucose administration, and glucose levels were estimated using a clinical glucometer.

2.8. Statistical Analysis. Results are expressed as mean\pm standard deviation (SD). The in vivo data were analyzed using one-way ANOVA, followed by Dunnett's post hoc test to compare blood glucose levels between control and test groups. A $p$ value less than 0.05 was considered statistically significant. The statistical analysis was carried out using the Statistical Package for the Social Sciences (SPSS) 20.0 version.

\section{Results}

3.1. Phytochemical Screening. Phytochemical investigation of the hydroethanolic leaves extract of $S$. pinnata revealed secondary metabolites such as saponins, phenolic compounds, flavonoids, and terpenoids (Table 1). The extract yield value was found to be $32.14 \%$ as calculated.
Table 1: Phytochemical screening of leaves extract of S. pinnata.

\begin{tabular}{lc}
\hline Test & Interferences \\
\hline Alkaloids & \\
$\quad$ (a) Mayer's test & - \\
(b) Hager's test & - \\
(c) Wagner's test & - \\
Glycosides (modified Borntrager's test) & + \\
Saponins (foam test) & + \\
Phenols (ferric chloride test) & + \\
Flavonoids (alkaline reagent test) & - \\
Tannin (gelatin test) & + \\
Terpenoids (Salkowski test) & \\
\hline
\end{tabular}

+: presence; -: absence.

3.2. Acute Toxicity Study. The maximum dose of $2000 \mathrm{mg} / \mathrm{kg}$ produced no mortality in rats. The animals did not manifest any signs of restlessness, respiratory distress, irritation, coma, or convulsions. Hence, the doses 250 and $500 \mathrm{mg} / \mathrm{kg}$ of $S$. pinnata leaves extract were considered safe for experimental purposes.

\subsection{In Vivo Hypoglycemic Activity}

3.3.1. Hypoglycemic Effect in Normal Rats. The effects of two different doses of $S$. pinnata leaves extract on blood glucose levels in normal rats were assessed, and the results are depicted in Table 2. Fasting blood glucose levels were within the range of $94.6-102.6 \mathrm{mg} / \mathrm{dl}$ in all groups at $0 \mathrm{~h}$. Both S. pinnata and metformin significantly reduced the fasting blood glucose levels in normal rats. S. pinnata- $(250 \mathrm{mg} / \mathrm{kg})$ treated group showed a distinct reduction in the blood glucose level after $3 \mathrm{~h}$ of extract administration. In contrast, the group treated with $500 \mathrm{mg} / \mathrm{kg}$ and metformin $(100 \mathrm{mg} /$ $\mathrm{kg}$ ) significantly reduced blood glucose levels at 1,2 , and $3 \mathrm{~h}$ after single-dose administration when compared to the control group.

\subsubsection{Hypoglycemic Effect in Glucose-Induced Hyperglycemic} Rats (OGTT). Experimental induction of hyperglycemia by oral administration of glucose $(2 \mathrm{~g} / \mathrm{kg})$ resulted in increased blood glucose levels after $30 \mathrm{~min}$ of glucose administration in all groups (Table 3). Fasting blood glucose levels were within the range of $92.8-98.6 \mathrm{mg} / \mathrm{dl}$ in all groups initially. S. pinnata- $(500 \mathrm{mg} / \mathrm{kg})$ - and metformin- $(100 \mathrm{mg} / \mathrm{kg})$ treated groups showed a maximum decrease in blood glucose levels at $3 \mathrm{~h}$ after single-dose administration when compared to glucose levels at $0 \mathrm{~h}$. S. pinnata $(250 \mathrm{mg} / \mathrm{kg})$ showed a relatively lower reduction in the blood glucose level at $3 \mathrm{~h}$. Therefore, the high dose $(500 \mathrm{mg} / \mathrm{kg})$ was more effective than the low dose $(250 \mathrm{mg} / \mathrm{kg})$ to lower the blood glucose level.

\section{Discussion}

Diabetes mellitus, popularly known as diabetes, is a global health problem and one of the leading causes of death worldwide. The latest data show that, around 463 million adults are surviving with diabetes [3]. Controlling blood 
TABLE 2: Effect of $S$. pinnata leaves extract on fasting blood glucose level in normal rats.

\begin{tabular}{lcccccc}
\hline \multirow{2}{*}{ Group $(n=5)$} & \multirow{2}{*}{ Dose $(\mathrm{mg} / \mathrm{kg})$} & \multicolumn{4}{c}{ Average blood glucose level $(\mathrm{mg} / \mathrm{dl})$} \\
& & $0 \mathrm{~h}$ & $0.5 \mathrm{~h}$ & $1 \mathrm{~h}$ & $2 \mathrm{~h}$ & $3 \mathrm{~h}$ \\
\hline Control & & $102.6 \pm 10.66$ & $105.8 \pm 13.08$ & $103.6 \pm 6.22$ & $100.2 \pm 7.15$ \\
S. pinnata & 250 & $94.6 \pm 6.02$ & $99.4 \pm 3.64$ & $99.0 \pm 10.09$ & $96.6 \pm 5.54$ & $91.0 \pm 8.7 .71$ \\
S. pinnata & 500 & $95.8 \pm 3.63$ & $105.0 \pm 4.35$ & $90.2 \pm 10.25^{*}$ & $84.2 \pm 10.13^{*}$ & $79.2 \pm 5.40^{*}$ \\
Metformin & 100 & $96.4 \pm 3.04$ & $98.4 \pm 6.18$ & $86.2 \pm 3.56^{*}$ & $78.2 \pm 4.49^{*}$ & $69.2 \pm 3.70^{*}$ \\
\hline
\end{tabular}

Values are expressed as mean $\pm \mathrm{SD},(n=5) .{ }^{*}$ Statistically significant when compared to the control group at $p<0.05$ (ANOVA followed by Dunnett's post hoc test).

TABLe 3: Effect of S. pinnata leaves extract on blood glucose level in glucose-induced hyperglycemic rats (OGTT).

\begin{tabular}{|c|c|c|c|c|c|c|}
\hline \multirow{2}{*}{ Group $(n=5)$} & \multirow{2}{*}{ Dose $(\mathrm{mg} / \mathrm{kg})$} & \multicolumn{5}{|c|}{ Average blood glucose level (mg/dl) } \\
\hline & & $0 \mathrm{~h}$ & $0.5 \mathrm{~h}$ & $1 \mathrm{~h}$ & $2 \mathrm{~h}$ & $3 \mathrm{~h}$ \\
\hline Control & & $98.6 \pm 7.50$ & $148.8 \pm 10.84$ & $120.6 \pm 12.77$ & $107.0 \pm 9.92$ & $100.2 \pm 7.56$ \\
\hline S. pinnata & 250 & $92.8 \pm 4.20$ & $112.4 \pm 8.79^{*}$ & $101.6 \pm 9.31^{*}$ & $95.8 \pm 8.34^{*}$ & $90.6 \pm 5.81$ \\
\hline S. pinnata & 500 & $96.0 \pm 5.24$ & $124.4 \pm 8.17^{*}$ & $103.4 \pm 7.05^{*}$ & $94.8 \pm 4.14^{*}$ & $82.8 \pm 4.43^{*}$ \\
\hline Metformin & 100 & $95.8 \pm 4.20$ & $127.8 \pm 8.16^{*}$ & $103.4 \pm 6.46^{*}$ & $89.0 \pm 6.51^{*}$ & $76.0 \pm 8.68^{*}$ \\
\hline
\end{tabular}

Values are expressed as mean $\pm \mathrm{SD},(n=5)$. *Statistically significant when compared to the control group at $p<0.05$ (ANOVA followed by Dunnett's post hoc test).

glucose levels is an essential intervention for treating and managing diabetes and related complications [23]. Until now, diabetes is being controlled with medications including allopathic, homeopathic, and traditional medicines [24]. Plant-based natural products have been used as a source of drugs since ancient times [25]. Research studies have shown that plants contain various bioactive compounds with known pharmacological activities [26, 27]. Different traditional medicine systems and folklore medicines utilize medicinal plants as a therapeutic aid for the management of diabetes [28]. For instance, Momordica charantia, Terminalia chebula, Acacia arabica, Eugenia jambolana, Allium cepa, Aloe vera, and Tinospora cordifolia have been widely used in crude forms and formulations for the treatment of diabetes in Ayurveda [29, 30].

In this study, the in vivo hypoglycemic activity of the hydroethanolic extract of $S$. pinnata leaves was investigated in normal and glucose-loaded hyperglycemic rats. S. pinnata leaves extract $(500 \mathrm{mg} / \mathrm{kg})$ and metformin $(100 \mathrm{mg} / \mathrm{kg})$ significantly reduced the blood glucose levels in normal rats at 1,2 , and $3 \mathrm{~h}$ on single-dose administration (Table 2 ). The results of the oral glucose tolerance test (OGTT) showed that metformin $(100 \mathrm{mg} / \mathrm{kg})$ and S. pinnata $(500 \mathrm{mg} / \mathrm{kg})$ reduced blood glucose level maximum at $3 \mathrm{~h}$ on glucose- $(2 \mathrm{~g} / \mathrm{kg})$ loaded rats (Table 3$)$. However, S. pinnata $(250 \mathrm{mg} / \mathrm{kg}$ ) was not able to improve glucose tolerance up to $2 \mathrm{~h}$ when compared to the fasting blood glucose levels. The significant reduction in blood glucose level observed may be due to the presence of phytochemical constituents that contribute to its hypoglycemic effect. Preliminary phytochemical screening of $S$. pinnata leaves extract revealed the presence of phenolics, flavonoids, saponins, and terpenoids, which may be responsible for its hypoglycemic action. Zheng et al. [31] reported that total saponins identified from Chinese medicinal plants significantly reduced fasting blood glucose and serum insulin levels and also eliminated oxidative stress in experimental rats. Terpenoids isolated from some antidiabetic medicinal plants have been found to stimulate insulin secretion from $\beta$-cells or mimic insulin action [32]. Steroids demonstrated significant antidiabetic activity by reducing the high blood glucose level and restoring insulin levels in streptozotocin-induced diabetic rats [33]. The possible mechanism by which plant extracts show antidiabetic activity may be attributed to bioactive compounds that may increase insulin secretion or its release from unbound forms [34]. In addition to the potent phytochemical constituents, it has strong free radical scavenging and moderate $\alpha$-amylase inhibitory activities [35]. $\alpha$-Amylase is an enzyme responsible for the digestion of carbohydrates. It hydrolyses $\alpha$-linked polysaccharides such as starch and glycogen and converts them into simple sugars such as glucose and maltose [36]. Inhibition of carbohydrate digesting enzymes delays glucose absorption and is thus a critical therapeutic approach for reducing postprandial hyperglycemia [5]. Hazra et al. [37] found that S. pinnata leaves and stem bark have high antioxidant and free radical scavenging activities and contain a large amount of flavonoids and phenolic compounds [37]. Flavonoids such as catechins improve glucose uptake by regeneration of damaged beta cells. Similarly, epicatechin gallate, epigallocatechin gallate, and epigallocatechin facilitate glucose mobility by activating transporters [24, 38]. Thus, the hypoglycemic activity of S. pinnata leaves may be attributed to certain phytochemicals such as flavonoids, saponins, terpenoids, antioxidants and $\alpha$-amylase inhibitory activity, as supported by various studies.

Several studies on different parts of S. pinnata have shown promising hypoglycemic and antidiabetic activities. It has been reported that methanol extract of the bark of S. pinnata produced significant antidiabetic activity in alloxan-induced diabetic rats [16]. The methanol extract of S. pinnata fruits exhibited a mild antidiabetic effect on alloxan-induced diabetic rats [17]. Another species of the genus Spondias, i.e., S. mombin leaves, possesses significant 
antidiabetic and antioxidant properties [39, 40]. Some potent secondary metabolites including flavonoids, phenolic acids, tannins, and triterpenes have been identified from S. mombin leaves [39-41]. Attanayake et al., [42] reported significant antihyperlipidemic and antihyperglycemic effects of aqueous bark extract of $S$. pinnata in streptozotocin-induced diabetic rats. The bark extract was able to induce $\beta$-cell regeneration in the pancreas of diabetic rats, which in turn increased the biosynthesis of insulin and improved glucose tolerance in S. pinnata-treated diabetic rats [42]. Likewise, the aqueous extracts of $S$. pinnata roots showed hypoglycemic activity with a significant decrease in blood glucose levels after four hours of treatment compared to glibenclamide in the oral glucose tolerance test [43]. Furthermore, our study on the hypoglycemic potential of leaves extract of $S$. pinnata has provided scientific evidence on the traditional use of the leaves for diabetes, and it is also the first in vivo hypoglycemic study of the leaves extract to our best knowledge.

\section{Conclusion}

Medicinal herbs have been used for the treatment and control of diabetes across the globe. S. pinnata leaves extract exhibited significant hypoglycemic activity in the animal model. The phytochemical constituents such as flavonoids, phenolics, saponins, and terpenoids might be the possible reason for its hypoglycemic action. Therefore, S. pinnata leaves may be a promising source of new antihyperglycemic agents, and a detailed mechanism-based study and isolation of bioactive compounds from S. pinnata would be beneficial in the future.

\section{Data Availability}

The data used to support the findings of this study are available from the corresponding author upon request.

\section{Conflicts of Interest}

The authors declare no conflicts of interest.

\section{Acknowledgments}

The authors would like to acknowledge the School of Health and Allied Sciences, Pokhara University, for space and laboratory facilities. Similarly, the authors would like to thank botanist Dr. Radheshyam Kayastha for identification of the plant species.

\section{References}

[1] A. D. Association, "Diagnosis and classification of diabetes mellitus," Diabetes Care, vol. 33, no. Supplement_1, pp. S62-S69, 2010.

[2] P. Saeedi, I. Petersohn, P. Salpea et al., "Global and regional diabetes prevalence estimates for 2019 and projections for 2030 and 2045: results from the International Diabetes Federation Diabetes Atlas, 9th edition," Diabetes Research and Clinical Practice, vol. 157, p. 107843, 2019.
[3] I. D. Federation, IDF Diabetes Atlas, International Diabetes Federation, Brussels, Belgium, 9th edition, 2019.

[4] S. Riaz, "Diabetes mellitus," Scientific Research and Essay, vol. 4, pp. 367-373, 2009.

[5] H. Keskes, K. Mnafgui, K. Hamden, M. Damak, A. El Feki, and N. Allouche, "In vitro anti-diabetic, anti-obesity and antioxidant proprieties of Juniperus phoenicea L. leaves from Tunisia," Asian Pacific Journal of Tropical Biomedicine, vol. 4, pp. S649-S655, 2014.

[6] H. Florido and F. Cortiguerra, "Lesser known edible tree species," Research Information Series on Ecosystems, vol. 15, pp. 1-8, 2003.

[7] W. Sujarwo and A. P. Keim, "Spondias pinnata (L. f.) Kurz.(Anacardiaceae): profiles and applications to diabetes," Bioactive Food as Dietary Interventions for Diabetes, Elsevier, Amsterdam, Netherlands, 2019.

[8] N. P. Manandhar, Plants and People of Nepal, Timber Press, Portland, OR, USA, 2002.

[9] W. Sujarwo, A. P. Keim, V. Savo, P. M. Guarrera, and G. Caneva, "Ethnobotanical study of Loloh: traditional herbal drinks from Bali (Indonesia)," Journal of Ethnopharmacology, vol. 169, pp. 34-48, 2015.

[10] M. N. Beidokhti and A. K. Jäger, "Review of antidiabetic fruits, vegetables, beverages, oils and spices commonly consumed in the diet," Journal of Ethnopharmacology, vol. 201, pp. 26-41, 2017.

[11] Y. Uprety, R. C. Poudel, J. Gurung, N. Chettri, and R. P. Chaudhary, "Traditional use and management of NTFPs in Kangchenjunga landscape: implications for conservation and livelihoods," Journal of Ethnobiology and Ethnomedicine, vol. 12, no. 1, p. 19, 2016.

[12] R. M. Kunwar, K. P. Shrestha, and R. W. Bussmann, "Traditional herbal medicine in Far-west Nepal: a pharmacological appraisal," Journal of Ethnobiology and Ethnomedicine, vol. 6, no. 1, p. 35, 2010.

[13] K. Sai, D. H. P. Devkota, R. Thapa, P. Poudel, and K. R. Joshi, "Free radical scavenging activity and chemical constituents of the unripe fruits of Spondias pinnata (L.f.) Kurz. from Nepal," Current Perspectives on Medicinal and Aromatic Plants (CUPMAP), vol. 3, pp. 54-60, 2020.

[14] D. Chaudhuri, N. B. Ghate, S. S. Singh, and N. Mandal, "Methyl gallate isolated from Spondias pinnata exhibits anticancer activity against human glioblastoma by induction of apoptosis and sustained extracellular signal-regulated kinase 1/2 activation," Pharmacognosy Magazine, vol. 11, pp. 269276,2015

[15] S. Tandon and R. Rastogi, "Studies on the chemical constituents of Spondias pinnata," Planta Medica, vol. 29, no. 2, pp. 190-192, 1976.

[16] S. Mondal and G. Dash, "Hypoglycemic activity of the bark of Spondias pinnata Linn. Kurz," Pharmacognosy Magazine, vol. 5, pp. 42-45, 2009.

[17] A. Sutradhar, A. P. Sarkar, M. A. Saleh et al., "Investigation of antidiabetic and antilipidemic effect of fruit extract of Spondias pinnata (Amra) in alloxan induced hyperglycemic rats," Journal of Pharmacognosy and Phytochemistry, vol. 7, pp. 2785-2789, 2018.

[18] D. Laksemi, "Biological activity of Spondias pinnata: a review," Indonesia Journal of Biomedical Science, vol. 13, pp. 88-93, 2019.

[19] E. Iqbal, K. A. Salim, and L. B. L. Lim, "Phytochemical screening, total phenolics and antioxidant activities of bark and leaf extracts of Goniothalamus velutinus (Airy Shaw) from 
Brunei Darussalam," Journal of King Saud University - Science, vol. 27, no. 3, pp. 224-232, 2015.

[20] S. B. B. Chhetri, D. Khatri, and K. Parajuli, "Antioxidant, antiinflammatory, and analgesic activities of aqueous extract of Diploknema butyracea (Roxb.) H.J. Lam bark," The Scientific World Journal, vol. 2020, Article ID 6141847, 6 pages, 2020.

[21] E. Walum, "Acute oral toxicity," Environmental Health Perspectives, vol. 106, no. suppl 2, pp. 497-503, 1998.

[22] S. T. S. Meonah, M. Palaniswamy, S. T. I. M. Keerthy, L. A. P. Rajkumar, and R. U. Nandhini, "Pharmacognostical and hypoglycemic activity of different parts of Solanum nigrum linn plant," International Journal of Pharmacy and Pharmaceutical Sciences, vol. 4, pp. 221-224, 2012.

[23] D. Khatri, S. B. B. Chhetri, P. Poudel, and N. Jamarkattel, "Hypoglycemic and analgesic activity of root extract of Rumex nepalensis," World Journal of Pharmacy and Pharmaceutical Sciences, vol. 7, pp. 730-743, 2018.

[24] A. K. Jugran, S. Rawat, H. P. Devkota, I. D. Bhatt, and R. S. Rawal, "Diabetes and plant-derived natural products: from ethnopharmacological approaches to their potential for modern drug discovery and development," Phytotherapy Research, vol. 35, no. 1, pp. 223-245, 2021.

[25] S. R. Devkota, K. R. Paudel, K. Sharma et al., "Investigation of antioxidant and anti-inflammatory activity of roots of Rumex nepalensis," World Journal of Pharmacy and Pharmaceutical Sciences, vol. 4, pp. 582-594, 2015.

[26] S. M. K. Rates, "Plants as source of drugs," Toxicon, vol. 39, no. 5, pp. 603-613, 2001.

[27] C. Veeresham, "Natural products derived from plants as a source of drugs," Journal of Advanced Pharmaceutical Technology \& Research, vol. 3, no. 4, p. 200, 2012.

[28] P. Arulselvan, H. A. A. Ghofar, G. Karthivashan, M. F. A. Halim, M. S. A. Ghafar, and S. Fakurazi, "Antidiabetic therapeutics from natural source: a systematic review," Biomedicine \& Preventive Nutrition, vol. 4, no. 4, pp. 607-617, 2014.

[29] M. Jung, M. Park, H. Lee, Y.-H. Kang, E. Kang, and S. Kim, "Antidiabetic agents from medicinal plants," Current Medicinal Chemistry, vol. 13, no. 10, pp. 1203-1218, 2006.

[30] I. R. Kundlikrao, "Antidiabetic drugs in ayurveda," International Research Journal of Pharmacy, vol. 4, pp. 21-24, 2013.

[31] T. Zheng, G. Shu, Z. Yang, S. Mo, Y. Zhao, and Z. Mei, "Antidiabetic effect of total saponins from Entada phaseoloides (L.) Merr. in type 2 diabetic rats," Journal of Ethnopharmacology, vol. 139, no. 3, pp. 814-821, 2012.

[32] T. Goto, N. Takahashi, S. Hirai, and T. Kawada, "Various terpenoids derived from herbal and dietary plants function as PPAR modulators and regulate carbohydrate and lipid metabolism," PPAR Research, vol. 2010, Article ID 483958, 9 pages, 2010 .

[33] P. Daisy, R. Jasmine, S. Ignacimuthu, and E. Murugan, "A novel steroid from Elephantopus scaber L. an ethnomedicinal plant with antidiabetic activity," Phytomedicine, vol. 16, no. 23, pp. 252-257, 2009.

[34] A. Yashwant Kumar, K. Nandakumar, M. Handral, S. Talwar, and D. Dhayabaran, "Hypoglycaemic and anti-diabetic activity of stem bark extracts Erythrina indica in normal and alloxan-induced diabetic rats," Saudi Pharmaceutical Journal, vol. 19, no. 1, pp. 35-42, 2011.

[35] K. Sai, R. Thapa, H. P. Devkota, and K. R. Joshi, "Phytochemical screening, free radical scavenging and $\alpha$-amylase inhibitory activities of selected medicinal plants from Western Nepal," Medicines (Basel), vol. 6, no. 2, pp. 1-9, 2019.
[36] E. Thilagam, B. Parimaladevi, C. Kumarappan, and S. Chandra Mandal, " $\alpha$-Glucosidase and $\alpha$-amylase inhibitory activity of Senna surattensis," Journal of Acupuncture and Meridian Studies, vol. 6, no. 1, pp. 24-30, 2013.

[37] B. Hazra, S. Biswas, and N. Mandal, "Antioxidant and free radical scavenging activity of Spondias pinnata," BMC Complementary and Alternative Medicine, vol. 8, no. 1, p. 63, 2008.

[38] K. Johnston, P. Sharp, M. Clifford, and L. Morgan, "Dietary polyphenols decrease glucose uptake by human intestinal Caco-2 cells," FEBS Letters, vol. 579, no. 7, pp. 1653-1657, 2005.

[39] A. Fred-Jaiyesimi, A. Kio, and W. Richard, " $\alpha$-Amylase inhibitory effect of 3 $\beta$-olean-12-en-3-yl (9Z)-hexadec-9-enoate isolated from Spondias mombin leaf," Food Chemistry, vol. 116, no. 1, pp. 285-288, 2009.

[40] B. Cabral, E. M. S. Siqueira, M. A. O. Bitencourt et al., "Phytochemical study and anti-inflammatory and antioxidant potential of Spondias mombin leaves," Revista Brasileira de Farmacognosia, vol. 26, pp. 304-311, 2016.

[41] J. Corthout, L. Pieters, M. Claeys, D. V. Berghe, and A. Vlietinck, "Antiviral ellagitannins from Spondias mombin," Phytochemistry, vol. 30, pp. 1129-1130, 1991.

[42] A. P. Attanayake, K. A. P. W. Jayatilaka, C. Pathirana, and L. K. B. Mudduwa, "Antihyperglycaemic, antihyperlipidaemic and cell regenerative effects of Spondias pinnata (Linn. f.) Kurz. bark extract on streptozotocin induced diabetic rats," European Journal of Integrative Medicine, vol. 6, pp. 588-596, 2014.

[43] S. Acharyya, G. Dash, S. Mondal, and S. Dash, "Studies on hypoglycaemic activity of the different extracts of Spondias mangifera willd root," Journal of Pharmaceutical Science and Technology, vol. 2, pp. 184-190, 2010. 